\title{
Growing up in a mainstream world: A retrospective enquiry into the childhood experiences of young adults with a physical disability
}

Sally Lumsdaine, Abertay University

Mhairi Thurston, Abertay Unversity

2016

This is the accepted manuscript of an article published by Taylor \& Francis in the International Journal of Disability, 2016 available online: http://dx.doi.org/10.1080/1034912X.2016.1194380 
Growing up in a mainstream world:

A retrospective enquiry into the childhood experiences of young adults with a physical disability.

Sally Lumsdaine, Abertay University

Mhairi Thurston, Abertay Unversity 


\begin{abstract}
Children with disabilities are at greater risk of developing mental health problems than their peers, yet the emotional well-being of this group is largely overlooked and there is scant literature about children with a mobility disability. This study examined the retrospective experiences of growing up with mobility disability. The sample comprised of 16-25 year olds with mobility disability. A thematic analysis, informed by grounded theory was used. Themes identified included a common socio educational journey, conflict between care and independence in school and the impact of being singled out because of disability out side school. The result was a range of psycho-social issues that affected participants view of themselves and the world around them. The study also looked at what the participants found helpful in dealing with the emotional impact of their disability. Whilst some sought help through talking therapies, others found involvement in disability sport was helpful.
\end{abstract}

Key-words: childhood disability, childhood mental health, mobility impairments, school inclusion, psycho-social barriers, disability sport. 


\section{Introduction}

It is well documented that there is an interrelationship between depression and physical health with those suffering poor physical health more at risk from mental health problems (World Health Organisation 2012). Despite this it is only recently that the World Health Organisation and UK Government have started to prioritise mental health issues with strategies such as 'No Health Without Mental Health' (2011), which seeks to address the inequality between the provision of mental health and physical health services in the United Kingdom. This link between mental and physical well-being is of particular importance where poor mental health affects treatment options and outcomes.

One group this affects disproportionately is people with disabilities. Recent statistics highlight that those with a disability are less happy, report lower levels of life satisfaction, are more anxious and feel less worthwhile than those without disabilities (Office for National Statistics, 2014). It is also known that depression and anxiety are associated with diminished health status and increased health care utilization (DiMatteo et al, 2000). This suggests treatment of mental health issues should be a vital component of the clinical care given. However, it has been reported that many people with disabilities have difficulty accessing mental health services and there is inadequate recognition of mental health issues within services for those with disabilities (DHSSPS, 2004).

Noh \& Posthuma (1990) suggested that evidence on the link between psychological well-being and disability is 'inconsistent and plagued with problems that raise questions about the validity and generalizability of many findings'. Part of this is because the term disability is overly broad as it encompasses a wide range of 
conditions and illnesses that are associated with a spectrum of need and ability including those with learning difficulties, physical disabilities and those with longterm health conditions. For a clearer understanding of the reality of any of these disability subgroups it is necessary to look within this homogenised sample to try to identify functional subpopulations that can provide useful information and specifically be used to inform and advise on aspects of living for individuals with that particular difficulty.

In terms of children with disabilities and long-term health conditions, what is known in general is that they are at a greater risk of developing mental health problems than their peers (Lavigne \& Faier-Routman, 1992, Hamall et al, 2014). It is also documented that children in this category are at greater risk for poor health outcomes (Jones, 2008), report a poorer quality of life (Edwards et al, 2003) and experience problems relating to their psychosocial well-being (Barlow et al, 2006).

Janssens et al. (2014) highlighted that whilst clinicians identified social and emotional functioning in children with disabilities as a core aspect of health they did not necessarily see this as part of their responsibility. This is despite an acknowledgment that mental health problems associated with these areas negatively impact on treatment adherence and control of the primary health condition. Mental health intervention has also been looked at in schools and whilst there had been an increasing range of school-based interventions it was found that pupils with emotional rather than behavioural difficulties were overlooked when it comes to the provision of specialist help (Research Report DFE-RR177). These findings suggest that there is an unmet need in terms of the emotional well-being of children with a disability in general. 
Medical and psychological teaching addresses childhood mental health in very general terms focussing on symptomatic presentations such as depression, anxiety and eating issues in isolation. A more holistic approach would consider the wider picture, taking account of the implication of any disability and how this impacts on the physical and mental health of the child.

In this study there is an assumption that children who grow up with a physical disability face multiple challenges to their mental and physical wellbeing. Aspects of their lives such as self-identification and autonomy struggle against the difficulties and the co-morbidities that can exist within a specific condition. What is seen is that some flourish and go on to lead fulfilling lives whilst others continually struggle to cope mentally and physically with their disability. This research intends to inform the debate around the experience of growing up with a disability, and factors that develop and sustain emotional resilience and psychological wellbeing.

Literature Review.

Whilst there is a significant amount of literature on disability in general, there is little information surrounding children with disabilities and more specifically children with physical disabilities. Watson (2012) writes that despite disabled children making up about $7 \%$ of the population, research in this area is still marginalised. The literature on childhood disability tends to explore this topic from the perspective of the parent or the professional and 'disability' itself is treated as a homogeneous categorisation with little or no differentiation being made for the nuances of those included within its boundaries.

This study suggests children with disabilities and long term health conditions experience social disadvantage (Blackburn et al. 2010, Bryan, 2004, Kitchen, 1998, Parson and Platt, 2013), face poorer outcomes in life (Clark and Hurst,1989, 
McConkey and McCormack, 1983) and are more prone to psychological and behavioural problems than their peers (Ammerman 1998; Breslau, N. 1985). Further studies have revealed that they are also at higher risk of bullying (Chatzitheochari at al., 2014), tend to be lonely (Huurre, T. M., \& Aro, H. M., 1998, Bakkalogle, 2009) and in general suffer low self-esteem (Richardson et al,1964, Anderson and Clarke, $1982)$.

Few of these studies, however, examine the experiential element of disability often viewing children as passive victims and not active agents in their own lives. Ali et al. (2001) assert that the disability movement in Britain in general has neglected children's experiences. In addition, Shakespeare (2005) highlights that disability studies need to "generate new and better accounts of disabled people's lives and the social exclusion they face".

Researchers have started this move toward a more experiential approach and significant here are the works by Watson, Shakespeare, Cunningham-Burley and Barnes (2011) on young people's experiences and perspectives of disability and Connors and Stalker (2006) which reports on the findings of a two year study of children with disabilities.

These studies start to paint a vivid picture of what it feels like to grow up with a disability. Watson et al. (2011) reported on experiences being limited by aspects of life such as adult surveillance or physical and communication barriers, whilst Connors and Stalker (2007) wrote about childhood disability being experienced in terms of impairment, difference, other people's behaviour, and material barriers.

This study continues in the vein of these writers and builds on the previous work by Thurston (2014) on inclusion and support for visually impaired students by 
endeavouring to highlight the voices of the individuals themselves and capturing what it feels like to grow up with a mobility disability.

\section{Method}

The aim of this cohort study was to investigate the impact of mobility impairment on children with congenital physical disabilities by retrospectively examining their childhood experiences using a qualitative approach.

The subjects were a self-selecting convenience group drawn from contacts identified through participation in disability sports groups, youth groups and attendance at disability clinics. Those selected for interview were school leavers between the ages of 16 and 25. All identified themselves as having a physical disability without any associated learning difficulties.

The final sample consisted of 10 participants: 6 females and 4 males, between the ages of 17 and 23 (mean age 20 years). Within the participant group, 6 subjects had Cerebral Palsy, 3 had Spina Bifida and 1 had a form of Muscular Dystrophy. All conditions were congenital and all but one participant were full-time wheelchair users.

Semi-structured interviews were carried out to give a better understanding of the emotional experience of growing up with a disability and whether this changed over time. The subjects were asked to retrospectively examine their childhood from approximately aged 5 by answering questions relating to aspects of their lives such as aspirations, friendships, inclusion and autonomy. Further questions went on to ask about mood and experiences of emotional distress relating to their disability. 
Analysis was approached using an adapted grounded theory methodology based on Strauss and Corbin (1990). An initial open coding system was used to identify categories. Themes were collated and grouped to reflect the issues that emerged from the interviews.

To test validity findings were re-distributed to participants. Eight participants gave feedback, all responded positively reporting the results gave a true indication of what it was like to grow up with a mobility disability.

\section{Results and Discussion}

The results that emerge from this study support and build on existing research (Watson et al.,2011; Connors and Stalker, 2007 and Hallum, 1995), where the lives of children with disabilities are explored from the perspective of the children themselves. Recognition is needed, however, of the diversity of need and ability within this section of society and because of this there is significant merit in trying to uncover the difficulties associated with growing up with a particular sub-classification of disability. Thurston (2014), for example, studied the experiences of children who are visually impaired and her research helped uncover the emotional impact of living in the unique world they inhabit. Similarly this study investigated the singular world inhabited by children with mobility impairments by retrospectively examining their experiences of growing up in a mainstream world.

Awareness and Identity.

The transition from childhood to adolescence is characterised by a development of self-identity and significantly positive self-identity is correlated with positive self- 
esteem (Rosenberg,1965). For the study group the development of a positive selfidentity was challenging and central to this was their perceptions around disability.

A key finding of the study related to the identification of an age of awareness around disability and difference. Before this age (often reported as being around adolescence), participants described themselves as being unaware of, or not acknowledging their impairments and accordingly felt more accepted and less 'disabled'.

"When I was younger I wasn't really aware I had a disability - well I was but it didn't hit me until I was about 13 or 14 and I realised - wait, I can't do that!" (P4)

"When I was young I didn't view myself as disabled - when I thought of myself then I thought I looked like everyone else." (P5)

“At Primary School I knew I was different but I chose to ignore it." (P2)

However at some point in time awareness around disability became heightened with many in the group reporting a change in the way they experienced themselves and others.

"In Primary kids were great cos no one knew any differently - no one had a problem cos no one understood, they were just accepting. But as soon as I moved to High School people treated me differently". (P4)

"I would say that I saw myself as the same as my Primary school peers but the older I got the more I realised, no there is a bit of us and them." (P6) 
This idea that notions of disability tend to occur at a later age is supported by Watson et al. (2011) who suggest that perspectives around disability are based on experience and concept with children being transformed by processes that reinforce difference and construct disability as a distinct classification. They argue that the way children with disabilities are discussed or the way social space is organised impacts on how they are represented, suggesting that the disabled label is externally created and imposed. Despite this, however, Watson et al. (2011) noted that the children within their study were "more ambivalent" about terming themselves as disabled. Similar to this Connors and Stalker (2007) found that most of the children with disabilities interviewed did not mention difference but focussed instead on their similarities to peers.

This apparent indifference to 'disability' contrasts with the findings of this study as, for the group interviewed, after this apparent age of awareness, 'disability' did matter and difference, in terms of the way they were seen, the way they were treated and the way they saw themselves, impacted on them significantly.

"I hated myself and my moods and when I saw myself I just saw the chair and no good parts." (P5)

"When I was about 13 years old I got depressed a lot about my disability. I started to resent my wheelchair and everything that was involved in my disability." (P8)

Significant here is the establishment of a self and social identity which is said to be a central task of adolescence (Butler,2010). This often involves such processes as peer comparison and self-evaluation in terms of appearance, ability and social relations, and is linked with mental health (Harter,1987) and self-esteem (Masten et al.,1995). 
However, according to Hallum (1995), reflection by adolescents with disabilities on difference is particularly painful and can lead to psychological crisis. Evidence of this emotional impact was seen within this study.

"Through my childhood I had a lot of sadness and self-loathing. As I got older I came to realise how my disability made my physical appearance different from others and I got to the point in High School where I'd cry myself to sleep almost every night" (P9)

"I knew I was different - like a freak" (P10)

There was even evidence that comparison with others was so painful that it caused isolation and withdrawal.

"I isolated myself - I withdrew socially from my school friends because it was easier than being around people who could walk - I removed myself cos I felt too different - there was too big a divide". (P1)

"I didn't want to be around people who were not like me" (P5)

"People just kept asking me if I was going to go to the Prom - and I thought really - like I am going to go to an event and watch the one thing I can't do - I mean the whole thing - I didn't like myself - and there was no way I was going to go to something where there would be dancing and photos." (P1)

Social integration.

Social integration is particularly significant as separating from one's parents and establishing relationships out with the family unit is seen as one of the major tasks of adolescence (Hallum,1995). What is more, this period is also described as a time 
when children spend increasing amounts of time with friends rather than parents (Larson and Richards, 1991). For the participants, however, adolescence did not necessarily bring this change in relationships. Instead, for some, it brought significant emotional distress.

One of the major impacts of disability described by the participants related to their ability to make and maintain friendships. Significant here is the fact that many of the group felt they had a peerless childhood where they existed between the disabled world and the able-bodied world often being the only child with a mobility disability within the mainstream of their school.

"I kind of discovered that I was too disabled to properly fit into the mainstream world but not disabled enough to comfortably fit into the disabled world." (P1)

"I was separately part of both worlds." (P2)

"I knew I had a disability but I didn't see myself like the others with a disability - I knew my disability was different - I didn't belong in that group”. (P3)

Alongside the difficulties some of the participants felt relating to not fitting in, other barriers to friendships were also described. Reeve (2204) writes about sociostructural and psycho-emotional barriers affecting what people can be and what they can do. Evidence was found of socio-structural barriers to friendships.

"My playschool wasn't in the catchment area for my Primary school so my friends all went to another school and I didn't keep in touch with these friends.. then my secondary school also wasn't in my catchment and whilst I 
made a couple a couple of friends in Primary school they didn't move onto my secondary school." (P6)

"At school I had a few friends but my disability made it difficult to be with children my age at home." (P9)

However of more impact on the group were the psycho-emotional barriers that were faced.

Hallum (1995; page 32) writes 'because of the triad of prejudice, stereotype, and discrimination, social attitudes toward people with physical impairments create barriers beyond those caused by the physical limitations alone'. Part of the journey described by many of the interviewees was a change in perception regarding social attitudes towards them by their peers.

"I was part of the conversation for the first couple of years - but then people just slowly and slowly isolated me - almost day by day and it got to the point where I didn't want to go see my "so called" friends if they were just going to exclude me". (P3)

"My friendships started to decrease as I wasn't able to keep up with everything they were doing". (P8)

This awareness around changes in attitude directly affected friendships and whilst exclusion to physical environments such as friends' houses or public spaces such as parks made socialising more difficult, what was of more concern to those interviewed was the way they viewed their relationships with their peers and how this affected their social integration in and out of school. 
"There was this group and I wanted to be part of it and I tried and tried - then I thought what is the point - it went on the whole way through school. " (P4)

"I mean I used to get angry cos I was different but I was a fool as well - I would like beg them - well instead of them meeting my needs I'd try my best to fit in with them.. To be with them and to please them - like part of me now regrets this cos at that point I was very unhappy about what I was doing and where I was". (P3)

Significant here were perceived notions around expectations of care and responsibility surrounding any friendships. The idea that being friends involved some form of care responsibility was seen to create resentment and reluctance to want to socialise especially outside of school hours. Described as 'the hassle factor' this unwillingness to amend or alter behaviour to accommodate the disabled peer in social activities was described by many.

"At the start they were fine, then they got annoyed that I was slower than them, then they got bored and didn't want to help me and then they ditched me and I was on my own... They said I'll wait for you - but they didn't.... I would go sit on my own - I even ate my lunch in the cubicle of the toilet..." (P10)

"I think people just think pushing me around was a hassle - it put them off they were like you push, no you push, no I did it last time... and stuff like that" (P3)

"I'd say you wanna come out (to my friends) and they would say, oh but there are stairs... and that was their way of telling me they couldn't be bothered.. If you had a real mate you wouldn't care you would just help." (P4) 
These findings correspond with Doubt and McColl (2003) who found that the extrinsic factors such as the attitudes and behaviours of non-disabled peers were barriers to social integration. However what is of note here is how that isolation made the participants feel.

"I felt deserted ". (P4)

"I didn't think about my disability until I was in Secondary when I slowly started getting isolated. Then I felt crap and I felt worthless and I felt like I was doing something wrong". (P3)

“At school I had no self-esteem, I didn't think I was good at anything, I didn't think I had any friends - I didn't think anyone wanted to be around me and I didn't want to be around anybody". (P5)

"I got very depressed and got very dark for a long time." (P1)

The School System.

It is generally understood that the transition to adulthood requires an increase in level of independence. However, participants identified a system in schools where rules around health and safety denied them the opportunity to attain independence and gain responsibility. Central to this was a conflict between care and autonomy where the participants perceived that the practices undertaken to support them were controlling, discriminating and ultimately 'disabling'.

In common with the findings of Watson et al. (2011) a high level of surveillance was found. 
"In secondary someone was always there and they wouldn't go and I would think - just go do your job with someone who needs you...it was annoying cos I couldn't even have a private conversation." (P8)

"I did feel like I was under surveillance- like I had the KGB on me or something”. (P6)

There was also a sense that the care given lacked flexibility and exerted undue control over the participants often highlighting difference or making them feel powerless.

"My teachers always tried to do things for me and tried to push my chair around even when I was perfectly able to do it myself." (P5)

"I did feel different from my peers as I was a lot more protected as the adults around me were scared I'd be hurt”. (P8)

"I wasn't allowed to go in the lift by myself - I just had to laugh.. I mean I would of got further along if I wasn't babied in that way”. (P2)

Another area highlighted was pseudo inclusion, where participants were denied full participation because of their disability. This was especially discussed in relation to PE where handing out bibs or playing the music was all that was offered in the way of involvement.

"It was hard to feel part of school - I was treated like I was fragile and in terms of PE and things - these were either adapted to the point where it was insulting or I was sent to sit at the side”. (P9)

"I always knew I was different - you always had to sit out or do something differently”. (P10) 
"In school they always had me do something in P.E. like put out the cones or play the music - I mean at least I was doing something compared to doing nothing - but that only started after my mum complaining that I was doing nothing in $P E ”(P 3)$

Again this impacted on how the participants felt about themselves.

"I couldn't do things the same way as everyone else or I couldn't do things at all and I kept being told you can't do that, you can't do that and I had it in my head - I can't do it , I can't do it!" (P10)

"There has sometimes been that feeling of being left out or being left to the side because of something I can't change" (P6)

Rob Kitchen (1998) writes about exclusion in terms of space and time and discusses the idea that institutions can work to keep people with disabilities 'in their place'. This form of exclusion was seen in schools with a number of participants reporting that they were refused access to communal spaces within schools because their wheelchair constituted a fire risk or that they were required to move from class to class out with the normal transition times for health and safety reasons. More than this, however, Kitchen points out that social oppression is a taught phenomenon as disabled people learn over time to fatalistically accept 'their lot'. Accounts of respondents being threatened with detention for practicing independent living skills or being afraid to break free of their carers would suggest that practices within schools can demonstrate this type of oppression. 
"Sometimes I did need a hand but often I was perfectly capable of doing things for myself but I was... well scared to say something - I didn't want to rock the boat but later I learned to say, thanks but I will get that” ( P4)

"At first I used a walking frame and that felt - well more normal as such because I was walking - but then I fell and they said it was a health and safety thing so I had to use a wheelchair - I also used crutches to try to be like everybody else but then I just had to accept it." (P2)

"I didn't know how to stand up for myself at school - I tried to but it just didn't come across the way I meant it to "- $(P 9)$

At school I wasn't allowed to use the life skills I was taught." (P6)

What is significant here is that the school system, which was set up to aid inclusion, was seen to do the opposite. As in the work of Thurston (2014) this highlights a model for inclusion that focusses on physical need to the detriment of socio-emotional development and negatively impacts on the child. The over control of pupils with physical disabilities and the tokenistic attempts at inclusion merely served to maintain feelings of inadequacy and highlight difference. Accordingly, what can be seen is the diminishing effect this system had on the participants and how it negatively affected self-esteem and ultimately mood and well-being.

"It was hard to be aspirational about my future when the important aspiration - to live an independent life always felt completely out of reach". (P9)

"Having a classroom assistant - they were always there and that was pointing out that I was different all the time." (P2) 
"I had some support through school - well they babied me and did everything for me - and I didn't realise that at the time until I moved it hit me - I thought wow, I have had everything done for me and that's really bad". (P3)

"I didn't feel positive being spoken to like I couldn't make my own decisions or take care of myself ... my teachers made me feel disabled" - (P9)

"I didn't want to spend my life being pushed around.. Like being a passenger in my own chair... the chair is my legs - and I'll use them the way I want" (P6)

"Let me go out and make my own mistakes" (P8)

Societal reactions.

Reeve (2004) describes the courage needed by a person with a physical disability when going out and writes 'it is the knowledge that each entry into the public world will be dominated by stares, by condescension, by pity and by hostility'. This mirrors the experiences of the cohort studied in that they highlighted the vulnerability and awkwardness felt being in the public eye.

Whilst there was a strong desire to be seen and treated as 'normal' their perceptions of how the world saw and treated them was very different.

"Most people see the chair before they see me as a person".( P3)

"I am just a normal person who just happens to be in a chair - so why be any different? - It is only my legs that don't work" - (P2)

"People just saw the chair and nothing else - and cos of this they treat you like you are below them - you don't do that - I mean, that is not right". (P9) 
The reaction of others was seen as a constant reminder of difference. Being stared at especially impacted negatively on some of those interviewed causing worry in some and eliciting anger in others.

"Day to day I worried about people staring at me - I mean that happened all the time especially with kids - but then I got more confident and before I got annoyed but I have grown out of that." (P4)

"Children on the bus - if they want to ask about my chair that is ok... but when they sit and stare - I hate that" - (P2)

Singh and Ghai (2009) write "staring results in a public stripping, leaving the object in a state of humiliation, highlighting their vulnerabilities in a very intense way". This form of disablism was part of the day to day reality for the group and seen as being at best an irritant and at worst as a deterrent to going out.

"Most of the time I don't leave the house cos if I leave I am scared - I don't want people to stare and I am fed up of just smiling and pretending." (P10)

Another area that was highlighted was that wheelchair use affected people's assumptions about them as individuals. Notions that they were seen as objects of pity were expressed by a number of the group whilst others highlighted that they felt that they were seen as incapable as or less able than they really were.

"People assume because you are disabled you must be slow in some way - you can tell by the tone of their voice - they speak slow with a happy tone... and like clichés you know - like you are an inspiration..." (P1)

"All people see is your disability - they just see the chair and they think you have a learning difficulty - they don't see you, your personality”. (P8) 
Interestingly, some of the group also found being offered help by strangers insulting and even linked the acceptance of help to feeling more 'disabled'.

"People just assume I can't do something because I'm in a wheelchair.. People just come up and assume they are going to help me, without me asking them that really really annoys me." (P3)

“..getting help packing a bag - or help off a bus - I will go out of my way to say no.. I suppose it goes back to that feeling more disabled - if you accept help you feel more disabled...." (P1)

The Emotional Impact of Disability.

All ten of the young adults interviewed reported going through some level of distress during their school years that was directly related to their disability. Issues around isolation, mistrust and injustice interwoven with desperation to be treated and seen as a 'normal', was seen to leave deep scars.

"I used to sob, a lot - I used to get really, really upset, what am I doing, why am I here..." (P4)

"I have had periods in my life when I have wanted to smash everything in sight." (P6)

"I have a lot of painful memories that still hurt very deeply". (P9)

"I had got to that point without telling anyone how I feel and well I just had to - well explode - as much as I could bottle it up until that point I just had to go into a room and scream”. (P1)

"I was very lonely". (P3) 
Within the group there was evidence of self-loathing, self-harm, depression and frustration which, like the earlier studies by Dorner (1976) and Anderson and Clarke (1982), suggests a link between psychological distress and disability. The findings of the study also corroborate the findings of Borjeson et al. (1990) who, in a study of disabled 15 to 18 year olds, found that the subjects felt that the social and psychologic effects of their disabilities were a greater problem than their physical impairments for which they had received the most help.

What helped.

Given that there was evidence of emotional distress across the group directly relating to their disability, the participants were asked what helped them to deal with these difficult feelings. What emerged was a mixed picture with the individuals seeking a range of interventions to help.

Most had not sought specialist help, but got support where it was most readily available, for instance, from their school or from their G.P. Three had seen counsellors, but not necessarily because of issues relating to their disability. Despite this, all felt that speaking to a counsellor at some point would have been helpful despite issues around understanding and immediacy. This corresponds with the findings of Thurston (2010) who established that the timing of counselling intervention and the sightedness of the counsellor was seen as being important to clients with a visual impairment.

There was some evidence that participants had used negative coping strategies such as self-harm and social isolation, whilst others had used more positive strategies such as actively trying to make sense of their disability emotionally and intellectually. Many 
displayed a fatalistic acceptance of their situation where there was an overwhelming sense that there was nothing that could be done other than just to 'get on with it'.

"I mean it is hard to accept but I got used to it- what can you do?" (P4)

"When I was younger I felt different and I wished I could walk and be normal but at secondary I started accepting it more and just getting on with it - sort of trying to ignore it.. “- $(P 2)$

"I just had to learn to accept it - like over time". (P8).

Possibly because of the nature of the cohort, one of the most significant findings was the positive influence of disability sport.

Disability Sport.

As many of the group were active within sports clubs it is unsurprising that this was highlighted as helping them overcome their emotional difficulties. What was surprising however was the depth of feeling about the activities undertaken in that they were not merely seen as a hobby but almost as a lifeline.

"Disability sport is about being around people who are like me, seeing how far they can go, how normal they are, it helps your self-esteem and helps you make friends - I don't know where I would be without it “-(P5)

"I see it as a lifestyle kind of - I mean how many new amazing people you can meet with different disabilities - I think it is just amazing - I have come a long way because of it and I am proud of that" - (P3)

“[Because of sport] I now have something to live for" - (P4)

Examining this more closely there are a number of factors that are significant. 
The health benefits of sport are well known but significant here is the psychosocial benefits of being involved with disability sport. In common with the earlier work of Anderson \& Clark (1982) and Dorner (1977) our study found that respondents spent a disproportionate amount time at home with their parents or siblings due to the restricted socialising opportunities out with school hours. Being part of a sports club helped here as it added structure and planned activity to the young person's week. The provision of a focus for their time and energy created a positive lifestyle for a number of our respondents and helped overcome feelings of boredom and loneliness.

"I think sport was a massive factor as we train during the week and sometimes at the weekend and we have away trips... this really helps as it does take up my time "- $(P 4)$

"I am focussing all my hard work and determination on wheelchair sports- I decided to go to the gym and push harder ... and because of that I now am training and playing lots.” (P3)

“Wheelchair sport has given me something to focus on" - (P2)

It has been widely documented that people with disabilities can feel socially isolated and are often socially marginalized (Thurston, 2010; Diamond, le Furgy, \& Blass, 1993; Anderson \& Clarke, 1982). It was found that playing wheelchair sports fostered a sense of belonging, as the participants, often for the first time, were able to feel understood and connect with others who felt like peers.

"It wasn't until I started sport that I saw anyone else that was disabled like $m e ”(P 1)$ 
"What helped me the most was joining the wheelchair sports club where I finally met people who understood". (P9)

Given the participant group advised that growing up they were often the only child with a physical disability within their school, the value of having role models cannot be underestimated. Taking part in disability sport offered the opportunity to meet other people with disabilities who were active and successful thus offering the individuals something to aspire to.

"Wheelchair sport definitely made me realise that these are guys who are disabled but it doesn't stop them doing anything - and that was the halleluiah moment for me - cos up until that point - nobody else was like me - like I couldn't make a connection and I sat between the two worlds". (P1)

"At wheelchair sports it is great cos most of the people do have a disability - it makes me see what I can do”-(P3)

Notions of equality were also discussed primarily due to the fact that in wheelchair sports, disability (and therefore difference) seemed to be 'taken out of the equation' as everyone participates in wheelchairs.

"With wheelchair sport the disability doesn't matter - there I am not disabled. From a purely visual standpoint I have exactly the same eye-level as everyone else - everyone is sat down and that is the only time that ever happens". (P1)

"you meet lots of people with a disability there - and you are able to talk to them about it, and you don't feel out of place - there I just felt normal cos everybody was in a chair". (P2) 
Another benefit of taking part in disability sports related to the opportunities it afforded to develop independence skills.

It has been well established that certain developmental tasks and skills are necessary for the transition from childhood to adulthood (DeBoor, 1975; The Cohen Council on Adolescent Development, 1995).The work by Buran et al. (2004) suggests that children with disabilities lack self-management and independence skills and link this to later psychosocial difficulties. Harrist (2012) identified the development of life skills was a central focus for both coaches and players in running basketball. Similarly with disability sport being part of a team and the associated need to travel and take part in group activities encourages the development of skills which facilitate independence and the development of personal responsibility, which in turn is seen to positively impact on self-esteem.

"Sport helped me grow up and be more confident, yeh and to do things for myself - even like going out, being confident around people. When I started I was shy and naive and lacked confidence but with sport.. It is not just about the taking part it is about learning life skills." (P4)

"I absolutely love wheelchair sports - you see they just accept me, they didn't have to .. but they believe in me and give me lots of opportunities.. it gives you lots of confidence" $-(P 2)$

The impact of disability sport on the group was clear and there was evidence of raised self-esteem, personal growth and improved emotional well-being.

"For the first time I felt that I was physically capable of doing something". $(P 9)$ 
"I have got involved with disability sport which has been huge in my development -the fact that I have actually started to be involved in things has helped my mood and helped me get back on track”. (P5)

- "I just think it is the best thing ever and without it I think I would be as depressed as I ever was". (P3)

Finally, and possibly most importantly there was a clear indication that being part of a wheelchair sports team had aided their acceptance of physical disability.

"And I weighed it up this way, if I was able bodied I wouldn't have done so much of the stuff I have done (with sport) - Life would've of been different if I was able bodied and I wouldn't like it”. (P2)

"Now if someone said I can take your disability away and you can be able bodied I wouldn't take it - I would stay the way I am... and I have discussed that with my disabled pals and they feel the same. \{So what has made the difference?\} - Sport”. (P5)

"I used to ask myself why me, why me.. of all the people why did this happen to me? But now I am glad it has happened and that is because of the sport - it has helped me accept it and be proud of who I am”. (P3)

\section{Limitations \& Future Directions}

There are a number of limitations that need to be taken into account in relation to this study. As with most qualitative studies the small sample size prohibits the findings being generalized more widely. This is especially true as this sample came from a 
cohort known to the researcher and was primarily drawn from a group who are actively involved in disability sport. Given that those that participate in sport are shown to have enhanced physical competence and higher self-esteem than their nonplaying peers (Martin, 2010) the sample used may not be representative of this group as a whole. Despite this, however, the results demonstrate that growing up with a physical disability, whether or not sport is played, impacts in a number of ways that cause emotional hardship. It is clear that this investigation has merely scratched the surface of the subject and has left many unanswered questions. Going forward it is recommended that further research is undertaken with a view to trying to establish what interventions might help address the issues identified. In addition another aspect of this research worthy of investigation relates to the link between sport and acceptance and whether participation in disability sport continues to help over the longer term.

\section{Conclusion}

Previous studies on the experiences of children with disabilities have tended to focus on a homogenised group consisting of people with all types of disabilities. This study aimed to focus particularly on a subgroup consisting of young adults with mobility impairments and aimed to retrospectively examine their experiences of childhood. The starting hypothesis suggested that children who grow up with this form of disability face multiple challenges to their physical and mental well-being. By evaluating the retrospective narratives of this group it was seen that the participants faced multiple challenges. This group seemed to come across difficulties relating to awareness and identity, social integration, school systems relating to care, and societal reactions to disability. Similar to the work by Reeves (2004) internal and external barriers were identified that contributed to the difficulties faced suggesting that 
emotional well-being and psycho-social functioning are affected by mobility impairment. It was, however noted that involvement in disability sport can moderate the negative emotional impact of disability by creating possibilities for personal growth, social integration and in some cases full acceptance of disability.

Word count 7084

\section{References}

Ali, Z., Fazil, Q., Bywaters, P., Wallace, L. and Singh, G. (2001) Disability, ethnicity and childhood: a critical review of research. Disability and Society, vol 16, no 7, pp 949-68.

Ammerman, R., Kane, V., Slomka, G.,Reigel, D., Franzen, M. and Gadow, K. (1998)

Psychiatric Symptomatology and Family Functioning in Children and Adolescents with Spina Bifida. Journal of Clinical Psychology in Medical Settings, Vol. 5, No. 4.

Anderson, E. M., Clarke, L. (1982) Disability in Adolescence. London: Methuen

Bakkaloğlu, H. (2010). A comparison of the loneliness levels of mainstreamed primary students according to their sociometric status. Procedia - Social and Behavioral Sciences, 2(2), 330-336. doi:10.1016/j.sbspro.2010.03.020

Barlow, J. H. and Ellard, D. R. (2006), The psychosocial well-being of children with chronic disease, their parents and siblings: an overview of the research evidence base. Child: Care, Health and Development, 32: 19-31. doi: 10.1111/j.1365-

2214.2006.00591.x 
Blackburn, C. M., Spencer, N. J., \& Read, J. M. (2010) Prevalence of childhood disability and the characteristics and circumstances of disabled children in the UK: Secondary analysis of the family resources survey. BMC Pediatrics, 10(1), 21-21. doi:10.1186/1471-2431-10-21

Borjeson MC, Lagergren J. (1990) Life conditions of adolescents with myelomeningocele. Developmental Medicine \& Child Neurology; 32:698-706 Breslau, N. (1985) Psychiatric Disorder in Children with Physical Disabilities. Journal of the American Academy of Child Psychiatry Volume 24, Issue 1, January 1985, Pages 87-94

Bryan, T., Burstein, K. and Ergul, C. (2004) The Social Emotional Side of Learning Disabilities: A Science-Based Presentation of the State of the Art. Learning Disability Quarterly February 2004 27: 45-51.

Buran, C. F., Sawin, K. J., Brei, T. J., \& Fastenau, P. S. (2004). Adolescents with myelomeningocele: Activities, beliefs, expectations, and perceptions. Developmental Medicine and Child Neurology, 46(4), 244-252. doi:10.1017/S0012162204000404

Butler, A. (2010) Adolescent Identity Development: Who We Are. http://www.actforyouth.net/adolescence/identity/ Cornell University.(2010) Chatzitheochari, S., Parsons, S. and Platt, L. (2014) Bullying experiences among disabled children and young people in England: Evidence from two longitudinal studies. Department of Quantitative Social Science Working Paper No. 14-11.

Clark, A. and Hurst, M. (1989) - Disability in Adulthood: Ten-year Follow-up of Young People with Disabilities. Disability, Handicap \& Society. Volume 4, Issue 3. 
Cohen, M. I. (1996) Great transitions, preparing adolescents for a new century. Journal of Adolescent Health, 19(1), 2-5. doi:10.1016/1054-139X(96)00028Connors, C. and Stalker, K. (2007). Children's experiences of disability: pointers to a social model of childhood disability. Disability \& Society 22, 1, 19-34

DeBoor, M, F. (1075) What is to Become of Katherine? Exceptional Children. 41: 517-518, doi:10.1177/001440297504100801

Department for Education; Me and My School; Findings from the National Evaluation of Targeted Mental Health in Schools 2008-2011: (Research Report DFERR177)

DHSSPS (2004) "Equality and Inequalities in Health and Social Care: A Statistical Overview” HEALTH AND SOCIAL WELLBEING: DISABILITY \& MENTAL HEALTH (DHSSPS, 2004:126).

Diamond, K., le Furgy, W., \& Blass, S. (1993). Attitudes of preschool children toward their peers with disabilities: A year-long investigation in integrated classrooms. Journal of Genetic Psychology, 154, 215-221.

DiMatteo, M.R., Lepper, H.S., Croghan, T.W. (2000) Meta-analysis of the Effects of Anxiety and Depression on Patient Adherence. Arch Intern Med. 2000;160:21012107 doi: 10.1093/jpepsy/jsg011

Dorner, S. (1976) Adolescents with Spina Bifida - how they see their situation. Archives of Diseases in Childhood, 51 pp 439-44 
Doubt, L. and McColl, M, A. (2003) A Secondary Guy: Physically Disabled Teenagers in Secondary Schools. Canadian Journal of Occupational Therapy June 2003 70: 139-151, doi:10.1177/000841740307000303

Edwards, T.C., Patrick, D.L. and Topolski, T.D. (2003) Quality of Life of Adolescents With Perceived Disabilities. University of Washington. J. Pediatric Psychology (2003) 28 (4): 233-241.

Hallum, A. (1995) Disability and the transition to adulthood: Issues for the disabled child, the family, and the pediatrician. Current Problems in Pediatrics, Volume 25 , Issue $1,12-50$

Hamall, K. M., Heard, T. R., Inder, K. J., McGill, K. M., \& Kay-Lambkin, F. (2014) The child illness and resilience program (CHiRP): A study protocol of a stepped care intervention to improve the resilience and wellbeing of families living with childhood chronic illness. BMC Psychology, 2(1), 5-5. doi:10.1186/2050-7283-2-5

Harrist, C. and Witt, P. (2012) A Qualitative Inquiry into Youth Basketball as a Positive Developmental Context. Journal of Sport Behaviour. June 2012; 35, 2.

Harter, S. (1987) The determinants and mediational role of global self-worth in children. In Eisenberg, N.(Ed), Contemporary topics in developmental psychology. (p219-242). New York. Wiley

HM Government. "No Health Without Mental Health" (2011); https://www.gov.uk/government/uploads/system/uploads/attachment_data/file/213761 /dh_124058.pdf

Huurre, T. M., \& Aro, H. M. (1998) Psychosocial development among adolescents with visual impairment. European Child \& Adolescent Psychiatry, 7(2), 73-78. 
Janssens A, Williams J, Tomlinson R,et al. (2014) Child Health outcomes for children with neurodisability: what do professionals regard as primary targets? ADC ONLINE published May 22, 2014 as 10.1136/archdischild-2013-305803

Jones, S. E. and Lollar, D. J. (2008) Relationship Between Physical Disabilities or Long-Term Health Problems and Health Risk Behaviors or Conditions Among US High School Students. Journal of School Health, 78: 252-257. doi: 10.1111/j.17461561.2008.00297.x

Kitchin, R. (1998) 'Out of Place', 'Knowing One's Place': Space, power and the exclusion of disabled people. Disability \& Society.Vol. 13, Iss. 3.

Larson, R and Richards, M (1991) Daily companionship in late childhood and early adolescence: changing developmental contexts. Child Development. 62: 284-300

Lavigne, J. V., \& Faier-Routman, J. (1992) Psychological adjustment to pediatric physical disorders: A meta-analytic review. Journal of Pediatric Psychology, 17(2), 133-157. doi:10.1093/jpepsy/17.2.133

Martin, J. (2010) The psychosocial dynamics of youth disability sport. Sport Science Review, XIX(5-6), 49. http://dx.doi.org/10.2478/v10237-011-0032-9

Masten A, Coatsworth J, Neemann J, Gest S, Tellegen A, Garmezy N. (1995) The structure and coherence of competence from childhood through adolescence. Child Development. 66:1635-59

McConkey, R. and McCormack, B. (1983) Breaking Barriers: Souvenir Press. London 
Noh, S., \& Posthuma, B. (1990). Physical disability and depression: A methodological consideration. Canadian Journal of Occupational Therapy, 57, 9-15.

Parson, S. and Platt,L. (2013) Disability among young children: Prevalence, heterogeneity and socio-economic disadvantage. Centre for Longitudinal Studies, Institute of Education, University of London.

Reeve, D (2004). Psycho-emotional Dimensions of Disability and the Social Model. Within Barnes, C. and Mercer, G. (2014) 'Implementing the Social Model of Disability: Theory and Research'; Leeds: The Disability Press, pp. 83-100).

Richardson, S. A., Hastorf, A. H., Dornbusch, S; M. (1964) 'The effect of physical disability on a child's description of himself'. Child Development, 35, 893-907.

Rosenberg, M. (1965) Society and adolescent self-image. Princeton, NJ: Princeton University Press

Shakespeare, T. (2005) Disability studies today and tomorrow. Sociology of Health \& Illness, 27: 138-148. doi: 10.1111/j.1467-9566.2005.00435.x

Singh, V. \& Ghai, A. (2009) Notions of self: lived realities of children with disabilities, Disability \& Society, 24:2, 129-145, DOI: 10.1080/09687590802652363

Strauss, A and Corbin, J, M. (1990) Basics of qualitative research: Grounded theory procedures and techniques. Thousand Oaks, CA, US: Sage Publications, Inc. 270 pp. Thurston, M. (2014) “They Think They Know What's Best for Me”: An Interpretative Phenomenological Analysis of the Experience of Inclusion and Support in High School for Vision-impaired Students with Albinism, International Journal of 
Disability, Development and Education, 61:2, 108-118, DOI:

10.1080/1034912X.2014.905054

Thurston, M., Thurston, A. and McLeod, J. (2010) Socio-emotional effects of the transition from sight to blindness. British Journal of Visual Impairment May 2010 28:

90-112, doi:10.1177/0264619609359304

Watson, N. (2012) Theorising the Lives of Disabled Children: How Can Disability Theory Help?. Children \& Society, 26: 192-202. doi: 10.1111/j.1099-

0860.2012.00432.x

Watson, N., Shakespeare, T., Cunningham-Burley, S. and Barnes, C. (2011) LIFE AS A DISABLED CHILD: A Qualitative Study of Young People's Experiences and Perspectives; http://disability-studies.leeds.ac.uk/files/2011/10/life-as-a-disabledchild-report.pdf

World Health Organization; Depression Fact sheet $N^{\circ} 369$ 